\title{
Energy Efficiency gap and the barrier models in France
}

\author{
Harishkumar a, ${ }^{\text {, }}$, Maheshkumar a \\ a Department of Electrical Sciences, Griffith University, Mount Gravatt, Australia.
}

*Corresponding Author hkofficial.1028@gmail.com (Harishkumar)

Received : 29 03 2019 Accepted : 11 05 2019

\begin{abstract}
In this article, attempt has been made to identify the energy efficiency gap in SME (Small Scale Enterprises) and LME (Large Scale Enterprises) in France and the various models involved in overcoming this barrier. These models involve implementing several techniques like Energy Audit or contracting energy management to a third party organization. This paper also discusses the motivating factors behind top level management for implementing energy efficient practices in an energy intensive organization. Finally, this article also discusses the importance of energy management technology and the use of implementing them in real world.
\end{abstract}

Keywords: EPC, ESCO, Energy efficiency gap

\section{Introduction}

The increase in energy consumption and hence the need for increased energy efficacy has been one of the objectives of countries like France. France being a key member in European Union, is a key player in hosting a range of industries. It has been the objective of France for the past decade to device policies that will culminate at a point where the industries are energy efficient and environment friendly. France is an easy study case and can be used to learn about the effective Energy management practices and be used to device benchmark for producing long term energy efficient schemes. Despite the existence of several energy efficient technologies there are several barriers, factors vary based on whether the firm under study is an SME or an LME, from implementing those technologies and achieve reduced energy consumption [1]. The gap that is perceived to be the difference between the optimal level of energy efficiency possible and the actual energy efficiency achieved is known as "Energy Efficiency Gap"[2]. All major approaches to the problem are classified in to supply side management or demand side management. In supply side management, the company achieves reduced energy consumption by reaching a consensus with the supplier to provide energy for lower cost. In Demand side Management, the company implements energy efficient technologies to achieve lower energy consumption. Discussing supply side management is beyond the scope of this paper as the problem itself is multidimensional. In the following sections several of the demand side management techniques are discussed. Previous study indicates that one of the most common and rewarding demand side management technique is performing an Energy Audit [3 4]. An Energy
Audit can easily point in the direction in which the company needs to focus to cut energy costs.

The next section discusses the several models explaining the existence of energy gap along with the driving forces that overcome those barriers.

\section{Barrier models}

There are several barrier models to explain the lack of energy efficiency that can be achieved. These barriers are mostly classified into: Economic,Behavioral and Organizational problems [5]. The economic barrier model explains the lack of encouragement from governments for companies to reduce energy consumption through means of Financial Aid or by providing room for further expansion [5, 6]. This barrier model is of great importance in explaining the energy efficiency gap in energy intensive industries like the foundry industries. These industries face fierce competition from underdeveloped nations, that have cost effective manufacturing process due to reduces labor cost [7].

This barrier can be overcome through governments providing direct fiscal subsidies to companies to implement energy efficient technologies as a part of their manufacturing assembly line. Several factors attribute to the intent top management, either individual or group, to drive the firm towards an energy efficient future. These factors are known as the Behavioral barrier. According to a study, the presence (absence) of energy efficient technologies in a firm is attributed to the intent(lack of intent) of the top management. People with real ambition in top management are the major factor to overcome such a barrier. 


\subsection{Energy management}

Energy Management can be done in many ways. Either the industry can invest in implementing an Energy efficient technology or it can device an energy efficient routine. Empirical study shows that up to $40 \%$ of total energy used can be saved in an energy intensive industry. One of the common energy efficient routines is to perform an Energy Audit. Energy Audit gives the company a top down view on energy consumption based on which the company can device plans to cut consumption. Apart from Energy Audit, the company can avail the service of Energy Service Companies (ESCO). An ESCO can help with consultation regarding implementing a new technology. ESCO can provide a range of services from providing financial aid to implement technology to manage the energy sector of a firm [7].Getting assistance from ESCO is key for a company, whose core is not Energy.

Other means of obtaining foreign body aid is by consulting a Third Party Funding (TPF) agency. Unlike ESCO, TPF can only aid with funding for implementing energy cutting technologies. Neither do these bodies possess extensive knowledge on newer technologies nor do they maintain up to date knowledge of various policies that shape energy management.

\subsection{External Driving Forces}

As stated previously, the presence (absence) of certain driving forces can explain the. In this section, various driving forces for increased energy efficiency are discussed. The most common driving force is the Financial Driving force. Some of attributes that are categorized in this factor are cutting taxes for firms that reduce $\mathrm{NO}_{2}$ and $\mathrm{CO}_{2}$ emissions. Reducing energy costs for reduced energy consumption. This driving force plays a vital role in Supply side Energy management.

Another driving force is the Information driving force. These forces come into play when the firm is exposed to other similar energy intensive companies pursuing energy efficient, cost cutting practices. In other words, these forces are set by example. Other ways of using this force is by spreading awareness of the methods of achieving energy efficiency and its advantages.

Organizational driving force is an internal driving factor. This force factor comes into play when the top management is committed to achieving energy efficiency. It is also achieved by networking among several departments within the firm. One study indicates networking among departments to the most important driving force for energy cutting.

Another important driving force is the External driving force. This is due to demand from customer or from environmental agencies that demand the firm to reduce the energy consumption. One of the most eminent external driving forces is the rising demand from all over the globe to reduce carbon emissions as mankind faces the threat of global warming. ESCO responsible for energy management can also play the role of external driving force.

One study involved interviewing people who were responsible for handling energy issues in their departments. This study was conducted across multiple firms in France [8].

\section{Results and Discussion}

Of the study pursued earlier, it was found that increasing energy costs to be the primary driving force behind energy efficiency implementation. Other driving forces were commitment from top management, tax reduction for reduced emission and intent. Of all the present barriers, the most dominant ones were organizational and financial barrier. Addressing these barriers in policy framing is of key importance for the government of France in paving way for energy efficient and environment friendly firms. Having such a policy can benefit the society and build a better future for everyone [4]. Another study emphasizes that Long term energy strategy is key importance in achieving a energy efficient Economy[8]. Finally having a more involved "role model" type public sector can play a key role in shaping the industrial sector's energy efficiency [9]. The impact of the above mentioned barriers may vary from industry to industry based on size and energy consumption. For example, a SME perceives that direct fiscal subsidies for cutting energy consumption and reducing emissions to be the key driving factor that medium and large enterprises that perceive people with intent to be the major driving factor.

\subsection{Potential for reduction of energy consumption}

One study indicated that companies that has never done energy audit previously has higher potential for reducing energy consumption than a company that has already done energy audit. More clearly, energy audit provides a company with greater awareness and provides insight in to setting a cleaner manufacturing process. Further analysis indicates that potential for energy intensive sector to reduce energy consumption in France depends on the room the government provides through means of fiscal aid or tax cuts. So, one can conclude that there is a higher need for companies to save energy when the governments frame policies that aim at improving the energy efficiency routines of companies. Further study indicates that the presence of a Long term Energy strategy is of key importance in shaping a company's energy routine. This agrees with the low percentage of energy intensive companies that have a long term strategy and are not energy efficient. Presence of a Long-term plan could shape the business model and shape energy management practices, which would further set the benchmark for that industry. Also, the potential for a company to improve its energy efficiency practices depends on the organizational driving factors. A company which has a top management with an intent to improve energy 
practices will more likely improve its energy routines, than a company whose top management lacks that intent. In worst cases, where the top management lacks the intent to improve energy efficiency, external driving factors could play a key role in inducing a motivation for the company to achieve better energy management. Also establishing an agreement with an ESCO or a TPC could improve the energy routines in favor of energy consumption. A study indicates that an ESCO or a TPC could improve the energy efficiency in an energy intensive firm by $7.5 \%$.Other forms of potential energy reduction schemes involve monitoring. Unlike Audit, monitoring gives a wide spread view of the energy consumption on a daily basis. Further one can device and view how the energy consumption and statistically categorize the energy usage for various departments in an industry.

\section{Conclusion}

Although one might argue the presence of intent in a company's top management to pursue efficient energy consumption practices to be a key player in judging the potential of a company to reduce the energy efficiency gap, study of other factors indicate that it is not the case. It is evident from our analysis that the presence of government policies plays a viral role in reducing the energy efficiency gap. The nature of these policies should be in such a way that a company is benefitted by reducing energy consumption by either being provided a direct fiscal subsidy such as tax cut for reduced emissions or a reduced energy cost for reduced energy consumption. Also, the presence of information related seminars or public sector role models could serve as an effective drive factor for companies to pursue energy efficiency as a field. Further, it is noted that improving energy efficiency could improve competition and hence pave the way for an eco friendly economy.

\section{References}

[1] G.O. Young, Synthetic structure of industrial plastics, in Plastics, $2^{\text {nd }}$ Ed., 3, J. Peters, Ed. New York: McGraw Hill, (1964) 15-64.

[2] W. K.Chen, Linear Networks and Systems. Belmont, CA: Wadsworth, (1993) 123-135.

[3] J. U. Duncombe, Infrared navigation-Part I: An assessment of feasibility, IEEE Trans. Electron Devices, 11 (1959) 34-39.

[4] E. P. Wigner, Theory of traveling wave optical laser, Phys. Rev. 134 (1965) A635-A646.

[5] E. H. Miller, A note on reflector arrays, IEEE Trans. Antennas Propagat. To be published.

[6] E. E. Reber, R. L. Michell, and C. J. Carter, Oxygen absorption in the earth's atmosphere, Aerospace Corp., Los Angeles, CA, Tech. Rep. TR O200 (4230 46) 3 (1988).
[7] J. H. Davis and J. R. Cogdell, Calibration program for the 16 foot antenna, Elect. Eng. Res. Lab., Univ. Texas, Austin, Tech. Memo. NGL 006 69 3 (1987).

[8] Transmission Systems for Communications, $3^{\text {rd }}$ Ed. Western Electric Co. Winston $\sim$ Salem, NC, 44-60(1985).

[9] Motorola Semiconductor Data Manual, Motorola Semiconductor Products Inc., Phoenix, AZ, (1989).

\section{About The License}

(C) 2019 The Authors. This work is licensed under a Creative Commons Attribution 4.0 International License which permits unrestricted use, provided the original author and source are credited. 